\title{
RELATIONS BETWEEN EPIDEMIOLOGY AND PUBLIC HEALTH
}

\author{
Martin Rusnák \\ Professor MD, CSc, Trnava University, \\ e-mail: martin.rusnak@ truni.sk, orcid.org/0000-0003-3321-1042, Slovakia \\ Viera Rusnáková \\ Professor MD, CSc, Trnava University, \\ e-mail: viera.rusnakova@truni.sk, orcid.org/0000-0002-1163-6675, Slovakia \\ Georges Kamtoh \\ $\mathrm{PhD}, \mathrm{MD}$, Polonia University in Czestochowa, \\ e-mail: georges2209@yahoo.fr, orcid.org/0000-0002-7897-5831, Poland
}

\begin{abstract}
The paper aims to discuss meanings of terms used in medical jargon to categorize activities with mostly disease preventive orientation. Based on definitions authors discussed scope of social medicine, public health, global health and epidemiology and their mutual intersections. Each statement is provided along with literature sources.
\end{abstract}

Keywords: public health, social medicine, global health, epidemiology.

DOI: http://dx.doi.org/10.23856/2615

\section{Introduction}

Health has traditionally been at the centre of society, not just professionals - healthcare professionals, but also politicians, economists and citizens themselves. It is a frequent topic of lay people's discussions, many of whom are interested in healthy life style, healthy eating, disease prevention, and ways of treating some of the illnesses that will affect them. Old recipes guaranteed by grandmothers, or traditions that are passed from generation to generation, are considered to be the best ways to deal with influenza or deal with a disease. At the same time, there is an increase in information about imported foreign methods that come from exotic countries, providing miraculous effect on reducing blood pressure, weight loss or diabetes. People ask where is the truth? Once, the doctors ordered one egg a day, now the eggs are forbidden. How do we know about it? What are we supposed to do to survive the longest possible life? How about alcohol? How much do I need?

Epidemiology is a biomedical science that helps with finding answers to many of these questions. It is sometimes difficult for practitioners to come with a single correct answer to some of the questions asked. An important aspect of looking for answers to these questions is knowing the health of society and its components. The actual identification of factors that are related to scattering of health or disease is the primary cause of epidemiology. Specific tools are immanent to epidemiology, that not only allow understanding of relations between health and disease, but also protect members of society from disease. The whole set of measures to prevent disease, to improve health, to provide health services is the content of what we call the health of society, in English "public health". This way the epidemiology is a part of this discipline as well as a very practical area of human efforts.

Authors will share basic views on both areas of biomedicine, public health and epidemiology and will define their scope. We will point to constant developments that bring them closer to other biomedical sciences. We will show that both are an essential part of trying to deepen the knowledge of health factors. It is not always easy to understand the 
context, especially when it comes to stochastic dependence (based on probability), so efforts to communicate these principles to the lay public are difficult, but more desirable.

\section{Definitions of public health}

The term "public health" has become familiar with the Central European countries of the nineties. This is one of the reasons why it is not yet recognized by the public, but also by biomedical experts at the level of clinical disciplines. Instead domestic and world media have repeatedly reported on epidemics, unusual childhood obesity, bioterrorism threats. Investments in reducing the frequency of smoking or road safety, which significantly contribute to improving the health of the population, rarely find adequate applause. On the other hand, the successful surgery of a unique health disorder is quoted in all means of mass communication. The fact that measures to improve public health resulted in Slovakia in life expectancy at birth extend by four years within two decades, and in Poland for 5,5 years, rarely appears in public. (Table 1) It may seem a minute, but it is important to acknowledge that behind each year of prolongation of this rate is the amount of deaths that have been delayed, or cases of early avoidance.

Table 1

\section{Life expectancy at birth by age and sex, years 1995, 2005 a 2015 in Poland and Slovakia}

\begin{tabular}{ccccccc}
\hline GEO/ & \multicolumn{3}{c}{ Poland } & \multicolumn{3}{c}{ Slovakia } \\
Year & Total & Men & Female & Total & Men & Female \\
\hline 1995 & 72,0 & 67,7 & 76,4 & 72,4 & 68,4 & 76,5 \\
2005 & 75,0 & 70,8 & 79,3 & 74,1 & 70,2 & 78,1 \\
2015 & 77,5 & 73,5 & 81,6 & 76,7 & 73,1 & 80,2 \\
\hline
\end{tabular}

Source: (EUROSTAT)

As the history of diseases confirms, the greatest impact on the rapid improvement of people's health, towns and nations does not come from discovering antibiotics, or coronary artery surgery, or innovative cancer treatments, but over the last three centuries, it has in particular been access to food, communal hygiene and protection from dangers. Medical science and services significantly contributed to the control of hazards, in particular through immunization and treatment. The theoretical assessment of human health determinants suggests that the same impacts are likely to be effective in the future as well. However, there is a difference that in developed countries personal behaviour (in terms of diet, exercise, tobacco, alcohol, drugs, etc.) is more important than providing food and controlling risks (McKeown, 2009; McKeown, 1976) and contribute to hygiene and contribute to improving and maintaining health, which naturally does not diminish the role of clinical medicine.

Usually we use the term "public health" to describe vast area of situations and activities oriented to protect and improve the health of population. Nevertheless, various definitions were used to specify the contents of the term, each highlighting a certain area that suits and supports specific policy. The founder of public health dr. Winslow published the first definition in 1920 (Definition 1). It still reads very modern, in spite of being almost 100 years old. It contains almost all modern concepts and issues, as reflected by newer formulations. Nevertheless, there are two points, that are addressed only recently: terrorism 
and global issues. There are some new contents added to original terms, but in general entire formulation is fully valid today and provides a message to all health professionals.

Public health is the science and the art of preventing disease, prolonging life, and promoting physical health and efficiency through organized community efforts for the sanitation of the environment, the control of community infections, the education of the individual in principles of personal hygiene, the organization of medical and nursing service for the early diagnosis and preventive treatment of disease, and the development of the social machinery which will ensure to every individual in the community a standard of living adequate for the maintenance of health.

\section{Definition 1 Public health as defined by Winslow in 1920 (Winslow, 1920)}

Frequently used definition (Definition 2) lists three main targets: preventing diseases, prolonging life and promoting health. Questions remain about how to make it happen. Science provides many examples of good practice, these days known under Evidence Based Public Health. (Brownson, Baker, Leet, Gillespie, \& True, 2010; Muir Gray, 2009). The art articulates that despite all known science and research there are still many areas of uncertainty, where our knowledge is limited because of missing evidence or the issue is too complex. It is concerned with change in the environment, in communities and in individual behaviour.

Public health is the science and art of preventing disease, prolonging life, and promoting health through organized efforts of society.

\section{Definition 2 Public health as defined by Achenson (Acheson, 1988)}

Formulation from the National Library of Medicine (NLM) is probably the closest to practice, because it clearly expresses the boundaries of the subject and its position (Definition $3)$. The third sentence within the definition expresses the links to clinical medicine as well as to biomedical research. The list of sciences, which are included is not exhaustive, one could emphasize molecular methodologies, as well data mining and big data. It clearly depicts the broad spectrum of disciplines, where from the public health practice and research profits.

Public Health is concerned with the prevention, detection, and control of disease, and the protection and promotion of health on a community or population level. Public health includes a set of biological, epidemiological, social, and statistical sciences and practices intended to measure, protect, and promote health on a population level. Public health overlaps many fields of medicine, given the growing population focus of biomedical research, the increasing concern with bioterrorism, and the importance of epidemiological methods in clinical trials. 2017)

Definition 3 Public health as defined by the National Library of Medicine (NLM,

Finally, the Centers for Disease Control and Prevention (CDC) went even further on with specifying details of public health scope (Definition 4). By providing examples for 
populations from the smallest local one to countries and regions current interests in global health are covered as well.

Public health the science of protecting and improving the health of people and their communities. This work is achieved by promoting healthy lifestyles, researching disease and injury prevention, and detecting, preventing and responding to infectious diseases. Overall, public health is concerned with protecting the health of entire populations. These populations can be as small as a local neighbourhood, or as big as an entire country or region of the world.

\section{Definition 4 Public health as defined by the Centers for Disease Control and Prevention (CDC) (Centers for Disease Control and Prevention, 2017)}

\section{From “Medicinischen Polizey" to global health}

Increased interest in health of people in the Anglo-Saxon world, especially in Britain since the end of the seventeenth century, was largely supported by philanthropic gentleman scientists. England promoted mass vaccination for profit, along with commercial waste disposal and street improvement. The question of human health in Britain has become linked to the changing role of the state in transitioning to the industrial society since the end of the 18th century. After 1815, the public treasury, deprived of the burden of massive military spending on the war, was increasingly devoted to domestic social policy. Public health policy has been the recipient of this development. In Britain, rapid industrialization transformed the demographic structure and geographical distribution of the population and escalated urbanization. British state explored new directions for the eradication of poverty and distress, which are based on Victorian expansion of voluntary efforts to provide services in health, education and housing. (Porter, 1999). This approach reflects the values of a society that favoured a minimal state influence.

Medicine in Central Europe has historically evolved under the influence of German schools, with an emphasis on the role of society, being represented by structures of the monarchy or other forms of central government, and on the other hand, local structures, especially cities. With the development of towns, the specific situations that arose from the accumulation of people on a small area grew the need to regulate the behaviour of individuals with regard to their health and the health of co-residents. The centralist tendencies in the Habsburg monarchy were reflected in the first book published in Central Europe, which summarizes the principles of public health protection for towns, under the title "System einer vollständigen medicinischen Polizey" (Frank, 1788). Johann Peter Frank, with his statecontrolled hygiene, laid the foundation for the first effective treatment of many diseases. The outcome was based on the knowledge that many diseases and their destructive widespread distribution arose in disastrous conditions, and it was not God's destiny. Frank contributed, through his numerous journeys and extensive correspondence, to spreading his idea of "hygienic police". (Exner, 2001). Today, many of the principles contained in this book are known under the term state health surveillance. This book was also addressed by Teofil Zacharias Huszty, a naturalist, a pre-urban physician and a pioneer in the vaccination of children against smallpox, who published a book titled Diskurs über die medizinische Polizei in Pressburg (today Bratislava). The result was the establishment of the Department of 
Medical Police at the Pest Faculty of Medicine. At the same time, it should be mentioned that dr. Huszty was a graduate from the Medical Faculty at Trnava University (Zólyomi, 1972).

A starkly contrasting model of public health development occurred in the United States. Here the reform was dominated by local voluntary efforts which were not initiated by aspiring specialist professionals. Instead, the reform was promoted by Puritan moral codes regarding social cleanliness and godliness. By the turn of the century a new technocratic ideal of social progress became influential, but this never succeeded in overcoming the persistent American suspicion of central government paternalism and a belief in the superior claims of local rights. The contrast with the British and other European models of reform highlights the multidimensional nature of the relationship between public health administration and the modern state (Porter, 1999). This development has led to the formulation of modern definition of public health by Winslow, as mentioned above. He also reflected the development in previous centuries: Public health conceived in these terms (see the Definition 1 above) will be something vastly different from the exercise of the purely police power which has been its principal manifestation in the past (Winslow, 1920).

In parallel, the Europe used the term "social medicine" to denote the role of the physician as an attorney to the poor and encouraged him to take up his duty to participate in the political planning of society. Furthermore, nineteenth-century sociology was born out of a medical metaphor which compared the analysis of social order to the analysis of living organisms (Porter, 1999). Nineteenth-century health and social reformers had been concerned with developing the political role of medicine in creating egalitarian societies. This concern continued to be a primary goal of twentieth century medical academics, such as Sand, who wanted to integrate medicine's social role into the training of physicians through the creation of a new academic discipline of social medicine (Porter, 2006).

Within international health organizations in the interwar years, supporters of social medicine as an academic discipline tried to undermine any exclusive focus on clinical medicine and pushed towards much broader social agendas. From the time of its establishment, the governing committee of the League of Nations Health Organization prioritized the development of social medicine. The International Labour Organization's representatives on the committee persistently argued that issues of social medicine could not be separated from the question of access to services that fundamentally affected the health of workers (Waitzkin, Iriart, Estrada, \& Lamadrid, 2001). After the World War 2 the AngloAmerican society developed a model of prevention that primarily focused on changing individual behaviour rather than addressing the social structural determinants of health and disease. The social medicine struggled to become institutionalized as an academic discipline which influenced medical education. While in Europe, the emphasis remained on both aspects: social determinants and behavioural change, with steady increasing gap between West and East. The fall of communist system outlined originally by Semashko in the early years of Soviet era, has led to replacing the term social medicine with public health, without necessarily changing the context.

New millennium brought people's safety to public attentiveness. Stories of Ebola virus outbreaks in west Africa exposed weaknesses in core global functions, such as the provision of global public goods, management of cross-border externalities and fostering of leadership and stewardship. Terrorism and migration crises accompanied with increased antibiotic resistance, vaccination refusals, burden from civilization diseases, climate change, and number of other threats to public health they all do not respect political or geographic borders or even continents. Consequently, public health on global level became not only an issue for 
professionals in the field, but politicians and lay public became sensitized, too. New term global health became frequently used by media and recognized by academic society. Two definitions illustrate the scope of the term (Definition 5).

Global health focuses on improvement of health worldwide, the reduction of disparities, and protection of societies against global threats that disregard national borders (Macfarlane, Jacobs, \& Kaaya, 2008).

Health problems, issues, and concerns that transcend national boundaries, may be influenced by circumstances or experiences in other countries, and are best addressed by cooperative actions and solutions (Institute of Medicine, 1997).

\section{Definition 5 Two definitions of Global Health}

\section{Epidemiology as basic science in public health}

Public health is considered an exact science encompassing naturally two components: objective and subjective. The first, objective one is mostly concerned with measurements and interpretation of results. The very ways of measuring mass phenomena in the population that affect human health are provided using the methodology of epidemiology. That would be not enough, society requires taking action responding to situation described by numbers or frequencies of occurrence. It is not enough just to know that four cases of infectious jaundice have occurred in our city's population during the weekend, but it is necessary to find a source and to take measures to prevent other people from getting sick. These and many other tasks are the subject of epidemiology, which we appropriately call the base science of public health. The definition contained in the Dictionary of Epidemiology (Porta, 2008) consists of two parts: the first refers to the search for the essence of health and disease, while the other on the exploitation of discoveries for the health of societies (Definition 6). The first represents the cognitive character of this discipline and its scientific basis. This naturally implies quantitative and qualitative approaches to scientific knowledge. The second part discusses the use of the results of the first one for addressing health issues. This is the extent of epidemiology, which is framed by procedures appropriate not only for understanding the health and disease conditions in the population, but also for interventions to improve, maintain or correct observed situations. While the first part consists mainly of methodologies for measuring health and its determinants, the second part deals with approaches and measures for implementing interventions. Epidemiology uses tools to measure the burden of disease in specific populations, including global, to determine differences in the burden of disease among populations, to examine the origin or causes of differences in disease burden, and to determine the effect of treatments and interventions to reduce disease burden. In other words, we can introduce epidemiology as a group of tools that we use to comprehend everything we understand about interventions, treatments, and health services.

The central theme of epidemiology are health conditions and related events. The history of epidemiology derives from the well-known London cholera event and its solution by Dr. Snow in Victorian England. Since then infectious diseases were the main cause of unhappiness for large groups of people, epidemiologists were primarily concerned about them. Later on, the interest has spread to endemic communicable diseases and noncommunicable chronic diseases, injuries, birth defects, maternal and child health, occupational health and the environment. In fact, the phrase "health status and phenomenon" 
may be considered to contain anything that affects the well-being of the population. However, many epidemiologists still use the term "disease" as an abbreviation for a wide range of health-related conditions and events that are being investigated.

EPIDEMIOLOGY The study of the occurrence and distribution of health-related states or events in specified populations, including the study of the determinants influencing such states, and the application of this knowledge to control the health problems. Study includes surveillance, observation, hypothesis testing, analytic research, and experiments.

Distribution refers to analysis by time, place, and classes or subgroups of persons affected in a population or in a society. Determinants are all the physical, biological, social, cultural, economic and behavioral factors that influence health. Health-related states and events include diseases, causes of death, behaviors, reactions to preventive programs, and provision and use of health services. Specified populations are those with common identifiable characteristics. Application to control... makes explicit the aim of epidemiology - to promote, protect, and restore health.

The primary "knowledge object" of epidemiology as a scientific discipline are causes of health-related events in populations. In the past 70 years, the definition has broadened from concern with communicable disease epidemics to take in all processes and phenomena related to health in populations. Therefore, epidemiology is much more than a branch of medicine treating of epidemics. There was a London Epidemiological Society in the 1850s. Epidemiología appears in the title of a Spanish history of epidemics, Epidemiología española. The term epidemic is much older; for instance, it appears in Johnson's Dictionary (1775), and the Oxford English Dictionary gives a citation dated 1603. The word was, of course, used by Hippocrates. 2008)

Definition 6 Epidemiology as defined in the Dictionary of Epidemiology (Porta,

\section{Concluding remarks}

Authors attempted to elucidate on terms used to characterise preventive activities on population levels. As terms "public health", "social medicine", "global health" and "epidemiology" each of them possessing specific historical and contextual connotations. Emphasis is placed on the role of epidemiology as a methodical basis for public health as well as the necessary convergence with biomedical clinical services. All disciplines discussed are used to specify activities towards helping people achieving good quality life.

An understanding of the sketched context should serve to promote the professional identity of health professionals engaged in public health as well as to provide a basis for development of health literacy and improving the health of people in their communities in global environment. 


\section{References}

Acheson, E. (1988). On the state of the public health [the fourth Duncan lecture]. Public Health, 102(5), 431-437. doi:https://doi.org/10.1016/S0033-3506(88)80080-5. [in English].

Brownson, R. C., Baker, E. A., Leet, T. L., Gillespie, K. N., \& True, W. R. (2010). EvidenceBased Public Health (2nd ed.): Oxford University Press, USA. [in English].

Centers for Disease Control and Prevention. (2017). What is Public Health? [Electronic resource]. Retrieved from http://www.cdcfoundation.org/content/what-public-health. [in English].

Eurostat (2017). Official site of European Commission. [Electronic resource]. Retrieved from http://ec.europa.eu/eurostat. [in English].

Exner, M. (2001). Von der Gesundheitspolizei zur globalen Vorsorge. Lebendiges Rheinland Pfalz, 38, 12-22. [in English].

Frank, J. P. (1788). System einer vollständigen medicinischen Polizey: Solwan. [in German]. Institute of Medicine. (1997). America's Vital Interest in Global Health. Washington, DC, US. [in English].

Macfarlane, S. B., Jacobs, M., \& Kaaya, E. E. (2008). In the name of global health: trends in academic institutions. Journal of Public Health Policy, 29(4), 383-401. doi:10.1057/jphp.2008.25. [in English].

McKeown, R. E. (2009). The epidemiologic transition: changing patterns of mortality and population dynamics. American journal of lifestyle medicine, 3(1_suppl), 19S-26S. doi:10.1177/1559827609335350. [in English].

McKeown, T. (1976). The Role of Medicine. London: The Nuffield Provincial Hospital Trust. [in English].

Muir, Gr. (2009). Evidence-Based Health Care and Public Health. How to Make Decisions About Health Services and Public Health (3rd ed.). Amsterdam, The Netherlands: Elsevier. [in English].

NLM. (2017). Collection Development Manual. [Electronic resource]. Retrieved from https://www.nlm.nih.gov/tsd/acquisitions/cdm/subjects89.html. [in English].

Porta, M. (Ed.). (2008). A Dictionary of Epidemiology. Oxford: Oxford University Press, New York. [in English].

Porter, D. (1999). Health, Civilization, and the State: A History of Public Health from Ancient to Modern Times. London and New York: Routledge. [in English].

Porter, D. (2006). How did social medicine evolve, and where is it heading? PLoS Medicine, 3(10), e399. doi:10.1371/journal.pmed.0030399. [in English].

Waitzkin, H., Iriart, C., Estrada, A., \& Lamadrid, S. (2001). Social medicine then and now: lessons from Latin America. American journal of public health, 91(10), 1592-1601. doi:10.2105/AJPH.91.10.1592. [in English].

Winslow, C.-E. (1920). The untilled fields of public health. Science, 51(1306), 23-33. [Electronic resource]. Retrieved from http://www.jstor.org/stable/1645011. [in English].

Zólyomi, N. D. (1972). Zacharias Gottlieb Huszty. 1754-1803: Mitbegründer der modernen Sozialhygiene (Vol. 1). Bratislava, SR: SAV, t. Svornost. [in German]. 